\title{
Contributors to Construction Debris from Electrical \& Mechanical Work in Hong Kong Infrastructure Projects
}

\author{
Sammy K. M. Wan ${ }^{1}$, Mohan M. Kumaraswamy, M.ASCE² and Davis T. C. Liu ${ }^{3}$
}

\begin{abstract}
:
The crucial problem of construction debris is of increasing concern in Hong Kong. In the construction industry, the electrical and mechanical (E\&M) installations in the infrastructure, whether buildings, tunnels or dams for example, are some of the major and usually complex components. Difficulty in coordinating the various trades affects productivity in general, and has a major impact on the quantity of construction debris. By identifying the sources of each stage of E\&M engineering work, some of the construction debris can be eliminated at the source during production. This paper investigates the critical production shortcomings in the E\&M sector in Hong Kong. The study is based on a survey that includes a preliminary questionnaire survey, brainstorming exercises with a focus group, structured interviews with experienced frontline supervisors and a second focus group exercise to test findings and proposed measures. The principal findings are that 'poor coordination' and 'design changes and/or errors' are a major contributor to variations or change orders and rework, in turn resulting in a high volume of construction debris. The results also indicate that construction debris can be minimised in the E\&M sector of the construction industry, if the material wastes from incidental work are reduced and also handled properly in a new work process flow pattern through recommended construction project management improvements for reducing critical production shortcomings.
\end{abstract}

CE Database Subject Headings: Construction debris; Coordination; Design; Electrical \& mechanical; Flow pattern; Production shortcomings.

\section{Introduction}

Construction debris has become a major source of solid wastes in Hong Kong and this is a specially pressing issue in Hong Kong where space is limited. According to "Monitoring of Solid Waste in Hong Kong - Waste Statistics for 2007” (EPD 2008), Hong Kong generated nearly 14 $\times 10^{6} \mathrm{t}$ of solid wastes in 2007 and about $21 \%$ or $2.91 \times 10^{6} \mathrm{t}$ are landfilled construction debris. Franklin and Andrews (2003) showed that it is not unreasonable to assume that the Electrical \& Mechanical (E\&M) sector accounts for a substantial amount of construction debris, in considering that between $40 \%$ and $50 \%$ of the total costs for office shell-and-core and fit-out projects are attributable to the E\&M sector. On the other hand, E\&M equipment may be replaced several times during the lifecycle of a construction development and are also likely to be disposed of as construction debris. The 'BSRIA Environmental Code of Practice for Buildings and their Services' pointed out that the E\&M sector is responsible for significant use of materials and release of environmentally unfriendly substances (Halliday 1994). Additionally, the 'BSRIA

\footnotetext{
${ }^{1}$ Head of Quality, Safety \& Environment, Analogue Group of Companies, 17/F, Java Commercial Centre, 128 Java Road, Hong Kong. E-mail: sammywan@atal.com.hk

${ }^{2}$ Professor, Department of Civil Engineering, The University of Hong Kong, Pokfulam Road, Hong Kong.

E-mail: mohan@hku.hk

${ }^{3}$ Chief Operating Officer, Construction Workers Registration Authority, 95 Yue Kwong Road, Aberdeen, Hong Kong. E-mail: davisliu@cwra.org.hk
} 
Guide - BG 16/2003' has indicated that the majority of material wastes in E\&M products, such as considerable amounts of E\&M fittings and accessories, are deposited in landfills (Olnhoff and Martin 2003). They indicated in the Guide that building services plant contain more material wastes mainly of metals, plastics and insulation materials, which could be glass or plastic, and the amount of metal and aggregate contents could be even more during refurbishment. It has become more important for Hong Kong in which about 9,300 private buildings in the metro area which are 30 years old and above and the number of ageing buildings over 30 years old will increase by $50 \%$ in ten years time (PLB 2001). Judging from this perspective, the debris mountain arising from the E\&M sector is huge and it continues to grow at an alarming rate. Given this trend in Hong Kong for example, the landfill and public fill sites will be filled up in 2010 (EPD 2007).

Shen and Tam (2002) pointed out that one of the barriers to implementing effective waste management in Hong Kong is the possible increment of costs due to additional investments on manpower, technology and facilities. There is therefore a dire need to recognize that reducing construction debris can also contribute to cost cutting. It has long been believed that the most effective way of dealing with construction debris is not to create it in the first place. Judging from this principle and provided that the construction debris can be minimized at its source, the quantity of construction debris can be effectively reduced and it is the most economical way to treat construction debris. This would focus on the most effective first " $\mathrm{R}$ " of the "Reduce, Reuse and Recycle” slogans.

It is noted that the above problem, while particularly acute in Hong Kong in prevalent in many regions. Therefore, the research approach and findings are expected to also assist those engaged in similar issues and research in other countries and regions. The issue of construction debris is important not only because of the extra disposal cost and limited space in landfill sites, but also because much debris usually arises from poor production management practices. For example, the construction cost would increase if the wrong materials are ordered or rectification works are required because of defective works, and higher construction debris levels can "symptomatically" signal such an underlying "disease" that may otherwise be "hidden". In addition to the costs of re-ordering and rectification, the delay may lead to extra recruitment of labour or engagement of machinery, and all these result in spiralling construction costs. Meanwhile, the extra construction project costs of replacement of installed works, including reworks arising from design changes, are magnified by the adverse effect of construction debris on the environment, and the negative added value of the additional work done. It therefore appears that if the production processes at different construction stages of an E\&M project can be improved based on a guiding principle for producing right the first time with minimal services crashes, the material wastes can be minimized and the quantity of construction debris can be effectively and economically reduced. However, research into production shortcomings including their causes which are hereinafter collectively considered to be "production wastes" in this study involves many variables, complexities and uncertainties. Furthermore, data from the E\&M sector of the construction industry in Hong Kong is not readily available, hence the launch of a synergistic study to address these issues together.

This paper is mainly concerned with management shortcomings in the E\&M sector of the construction industry in Hong Kong. The paper first introduces the concept of production wastes that contribute to construction debris in the course of work arising from management or production shortcomings. Several previous studies are discussed, after which a new "flow pattern" for construction debris is suggested and conceptualised. Furthermore, a series of interviews with 15 experienced frontline site supervisors involved with E\&M works in Hong Kong infrastructure projects are presented, discussed and analyzed. The results contribute to an 
identification of critical production wastes in the E\&M sub-project at different stages of the construction project, indicating that minimization of those production wastes can effectively reduce construction debris and enable the practical implementation of the suggested new flow pattern as conceptualised in this paper.

\section{Overview}

The following descriptions begin with a review of the concept of production waste and its impact on the extent of the construction debris in the E\&M sector of the construction industry. For easy identification, construction debris is taken to generally represent the material wastes that can be collected at public fill or landfill sites. Furthermore, the nature of the less visible E\&M sector should be explained in order to bring the general readers' attention to the complexity and speciality of this sector of the construction industry. In Hong Kong, the E\&M systems within the construction industry can be classified into three categories, that are mechanical, electrical and building operation systems (Tao and Janis 1997). In reality, the E\&M installations are some of the major and complex construction components because of the many uncertainties, contributors and dependencies on others. Additionally, the construction works involved often depend on, and overlap with each other and cannot afford delays at any stage. Hanna et al. (2002) investigated the productivity of E\&M trades in 2002 and identified that the E\&M installations are high-risk and labour intensive undertakings with low profit margins (i.e. 3-4\%) and high ratio of labour cost per total cost (i.e. 40-60\%). In fact, the sector continues to face the pressures of rising costs, shrinking profit margins and intense competition. The foregoing observations suggest that manpower coordination of separate or sequential trades and the reduction of avoidable production costs are in dire need of improvement.

\section{Concept of Production Waste}

In a traditional manufacturing plant, production wastes are taken to mean those that tend to increase the overall cost without adding any value to the end product. Toyota has described production waste as anything that is different from the minimum quantity of equipment, material, parts and labour that is absolutely essential for production or necessary to add value to the product (Ohno 1988). In other words, production waste is defined as those activities and behaviours that add cost but do not add value as perceived by end-use customers (Emiliani 1998; Ohno 1988; Womack and Jones 1996). Once production waste has been identified, it can then be minimized.

Shingo (1981) classified seven deadly production wastes that are most prevalent in manufacturing plant, in studying the Toyota manufacturing system, namely overproduction, waiting, transport, system, stock, operation and defects. Plossl (1991) added three more production wastes, i.e. people, time and bureaucracy, and Standard and Davis (1999) added one equally significant waste on top of Shingo's seven deadly production wastes to show that unrealized human potential plays an important role in generating those production wastes.

Unlike the manufacturing industry, the construction industry is quite complex, for example given that site conditions are very variable, unlike factory conditions, while projects are short-term. The many variables in conditions and resource inputs thus generate much more non value-adding activities leading to low productivity. Borcherding and Alarcón (1991) indicated in their qualitative model that five categories of production wastes are the causes of reduced productivity in construction projects. They are waiting or idling, travelling, slow work, ineffective work and 
rework. It is therefore interesting to note that despite the causes of industry differences, production wastes in the construction industry are similar to those that have been identified in the manufacturing industry. Alarcón (1994) conducted a study to identify and reduce production wastes in construction projects and presented the most frequent on-site waste sources in respect of three areas including administration, use of resources and information systems. Koskela (1992) claimed that an analysis of a series of flow and conversion activities contributes to developing more reliable and smoother processes in order to achieve "lean construction". He postulated that only "conversion activities" where the materials are processed can be considered value-adding, while the other "flow" activities that do not add value to the product can be classified as production wastes. He has also contended that "making-do production waste" should be added as the eighth category of waste in addition to the seven deadly production wastes so as to incorporate the situation where a task is started without all its standard inputs or certain inflows (Koskela 2004). It is of course possible to add more categories of production wastes and organizational wastes, but these may be added with care, according to their context and potential significance in a given domain. For example, as suggested by Macomber and Howell (2004), "not listening” and "not speaking” may also play a role in everyday project coordination.

Table 1. Summary of Major Production Wastes that Lead to Construction Debris as Identified by Various Researchers

_ Major Category of 'Production Wastes’

\begin{tabular}{|c|c|c|c|c|c|c|c|c|c|c|}
\hline Researchers & 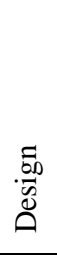 & 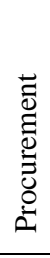 & 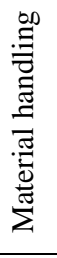 & 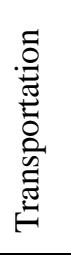 & 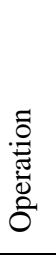 & 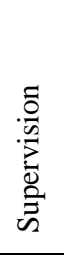 & 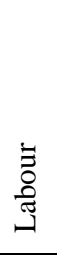 & 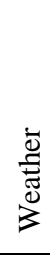 & 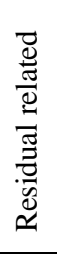 & $\begin{array}{l}\mathscr{n} \\
\tilde{\Xi} \\
0\end{array}$ \\
\hline Gavilan and Bernold (1994) & $*$ & $*$ & $*$ & & $*$ & & & & $*$ & $*$ \\
\hline Vaid (1996) & $*$ & & * & & & & $*$ & & & \\
\hline Bossink and Brouwers (1996) & * & & * & & & & & & & \\
\hline Faniran and Caban (1998) & $*$ & & $*$ & & & & & $*$ & $*$ & $*$ \\
\hline Jayawardane (1998) & & & * & & & * & * & & & \\
\hline Formoso et al. (2002) & & & & & & $*$ & & & & $*$ \\
\hline Ekanayake and Ofori (2004) & $*$ & $*$ & $*$ & & $*$ & & & & & \\
\hline Urio and Brent (2006) & $*$ & $*$ & $*$ & & * & & & & $*$ & $*$ \\
\hline Tam et al. (2006) & * & * & & * & * & & & & & \\
\hline
\end{tabular}

\section{Causes of Construction Debris}

Other researchers have previously investigated, or noted for future investigation, the potential interrelationship between production wastes and construction debris in the construction industry. Over 30 years ago, Skoyles (1976) admitted that there is an unacceptable level of construction debris that can only be reduced through a significant upgrade in the production system. Gavilan 
and Bernold (1994) observed and analyzed different construction processes and categorized the sources of construction debris into "design, procurement, handling of materials, operation, residual and others not listed”. Vaid (1996) indicated in his productivity study on mass housing projects that poor design, material mismanagement and non-commitment of site personnel are the main causal factors of the high levels and rates of construction debris. Bossink and Brouwers (1996) investigated the prevention of construction debris in the Netherlands and suggested that the main causes of construction debris are related to upstream processes such as design and material handling. Faniran and Caban (1998) revealed a similar result from his survey and categorized typical construction debris sources into design change, design error, leftover material scrap, packaging and non-reclaimable consumables and poor weather. Jayawardane (1998) conducted a pilot study in Sri Lanka and contended that a considerable amount of construction debris is mostly due to improper management of sites including material handling, supervision and concerns of labour. Formoso et al. (2002) pointed out in his study on the Brazilian building industry, that most of the construction debris could be avoided by implementing managerial improvements. Ekanayake and Ofori (2004) applied multi-attribute value techniques under design, operation, material handling and procurement related areas, and suggested that design is an essential contributor to reducing construction debris.

All the above studies indicate that construction debris can be reduced through process improvements throughout the entire construction cycle. In the meantime, most of the researchers acknowledge that design has a major influence on material wastes or construction debris (See Table 1). However, it seems that no previous studies have probed the complex, uncertain and labour intensive E\&M sector of the construction industry. The current study in Hong Kong thus addresses this research gap in an academic sense, and develops useful insights that could inform industry improvement strategies. This research gap has been identified by the building waste assessment study conducted by Ekanayake and Ofori (2004).

\section{Conceptualizing the Flow Pattern of Construction Debris}

A new conceptual model of the flow pattern of construction debris is developed, following a surge of interest in the manufacturing classification of production work. It is undeniable that not all the construction debris in a typical construction site is avoidable. Skoyles and Skoyles (1987) have generally categorized construction wastes into direct and indirect wastes. Direct waste is a complete loss of materials due to the fact that they are irreparably damaged or simply lost, and indirect waste is distinguished from direct waste in that the materials are not usually lost physically. Similar to the manufacturing industry, the total construction debris is now divided into three portions including debris from value-added work, debris from incidental work and debris from production wastes (See Fig. 1). Indirect construction debris and production waste from incidental work are very often overlooked. This is created during the accompanying but indispensable processes in construction, such as submission and approval, purchasing, inspection, audit, meeting, operation manual preparation and training. The non value-added design change, defect, rework, etc., contribute to production wastes that have no value in the eyes of the customer. These non value-added works may also generate construction debris even though the quantity is difficult to measure or ascertain in different construction projects.

It is suggested that before dumping construction debris from the construction sites to the increasingly overloaded public fill or landfill sites in Hong Kong, as much as possible of the production wastes produced from the incidental work should be reduced or even replaced by value-adding work while the construction debris from the production wastes should be minimised. As discussed above, incidental works have to be properly and effectively managed in 
order to alleviate the volume of indirect construction debris that may be produced. Then, how can the said works be properly and effectively managed ? In practice, "partnering" may be one of the possible solutions to replace unnecessary incidental works by value-adding works. Mutual trust, objectives and cooperation among the project teams can reduce distrust and multiple checks and supervisory layers in a successful partnering programme. Through these savings and faster problem-solving, some, if not all, of the incidental works can be streamlined through effective partnering, simplified and become less bureaucratic so that more efforts and time can be diverted to more value-adding works. These benefits can arise from integrating the otherwise fragmented project teams, which are usually composed of members from different organizational cultures, and with divergent objectives at the outset (Kumaraswamy et al. 2005).

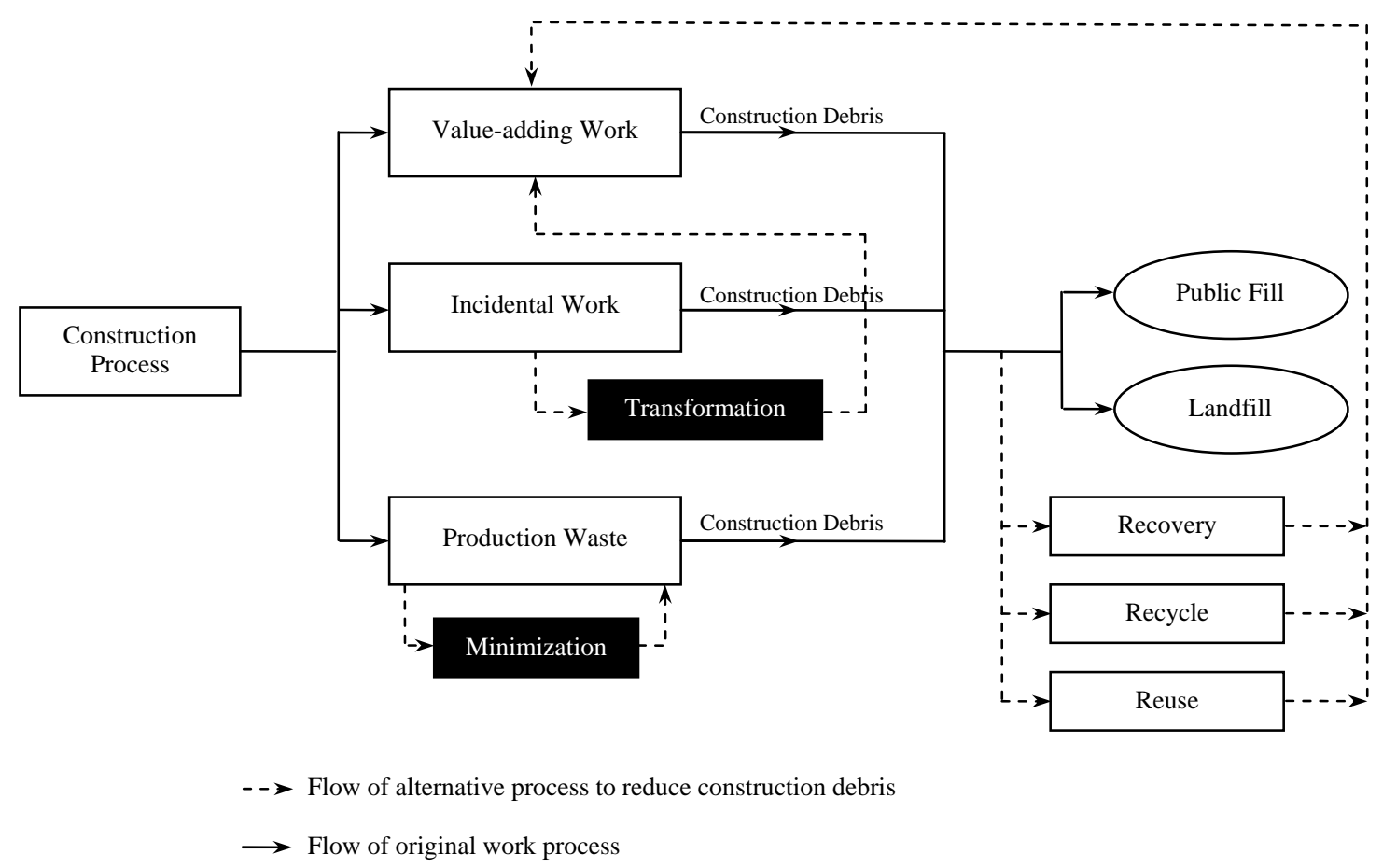

Fig. 1. Flow pattern of construction debris in a typical construction project with improvement strategies

Modern technologies can also play a role in changing or diverting incidental works to valueadding works. For example, the barcode asset management system has been recommended in the "BSRIA Guidance Note - ACT 5/2002" to make life easier in the processes of procurement, installation, inspection, testing, etc. on site (Dicks 2003). Each building component has already been codified in this system so that its status can be retrieved readily on line to save a tremendous amount of time and efforts in delivering the incidental works and more resources can then be diverted to the value-adding works. In parallel, construction debris can further be recovered, recycled and reused before final disposal to minimize the impacts on the environment.

\section{Survey of Production Wastes in the Electrical \& Mechanical Sector}

Generally speaking, it is an efficient approach to identify the real causes of construction debris before minimisation because much of the present levels of construction debris will not be created 
in the first place (Gavilan and Bernold 1994; Snook et al. 1995). In order to translate into practice the suggested strategies in Fig. 1, on a revised flow pattern of construction debris, it is necessary to identify and reduce the critical production wastes that contribute to construction debris over the whole construction process of an E\&M project. Before the in-depth structural interview study, a preliminary questionnaire survey was successfully conducted with the support of the Hong Kong Federation of Electrical and Mechanical Contractors in the period between February and April 2006 and 200 questionnaires were sent to the senior practitioners in the E\&M sector in Hong Kong. The practitioners included managing directors, senior project managers, senior engineers, principal consultants, senior quantity surveyors and government officials. A tailor-made questionnaire with a 1 to 5 scale of magnitude was used in this preliminary survey and a total of 37 questionnaires were returned and the highly rated production wastes with a score of between 4 and 5 were classified as positive responses. This survey showed that the production wastes of "coordination problem", "change of design", "rework and/or variation work", "ineffective and/or unclear communication", "delay of work activities" and "excessive inspections and/or supervisors" were found to be the most critical items compared to other production wastes as perceived by the respondents, and these items contribute nearly $30 \%$ of the total production wastes in the E\&M sector.

\section{Brainstorming Exercise}

The critical production wastes that hinder the whole E\&M sector in Hong Kong were perceived by the senior practitioners in the E\&M sector identified but it is also necessary to understand the production wastes from another point of view of the frontline site supervisors in the sector that may be encountered and will contribute to construction debris in the course of work. Before arranging a planned interview survey with frontline site supervisors and based on the findings as identified in the previous preliminary questionnaire survey, a brainstorming exercise was performed on August 5, 2006 with a specially convened focus group meeting of 10 senior and mid-level construction practitioners including the first and third writers so as to identify the common and potentially serious production wastes factors that adversely affect the performance over the whole process of an E\&M construction project. The responses and comments received via the preliminary questionnaire survey and brainstorming exercise were reviewed in light of relevant studies and available sources of reference for developing another structured interview survey.

The results of the exercise were recorded in a cause and effect diagram or Ishikawa diagram, as in Fig. 2. Fig. 2 aims to map the linkages between causes and effects. The ultimate effect is the generation of critical production wastes in the E\&M works in a construction project, and the contributory causes are shown as the contributory branches in the diagram. This cause-and-effect diagram was the main reference tool used for interview surveys, observations and dialogues with frontline site supervisors in order to trace the critical production wastes frequently occurring at different stages in the course of an E\&M construction project. 


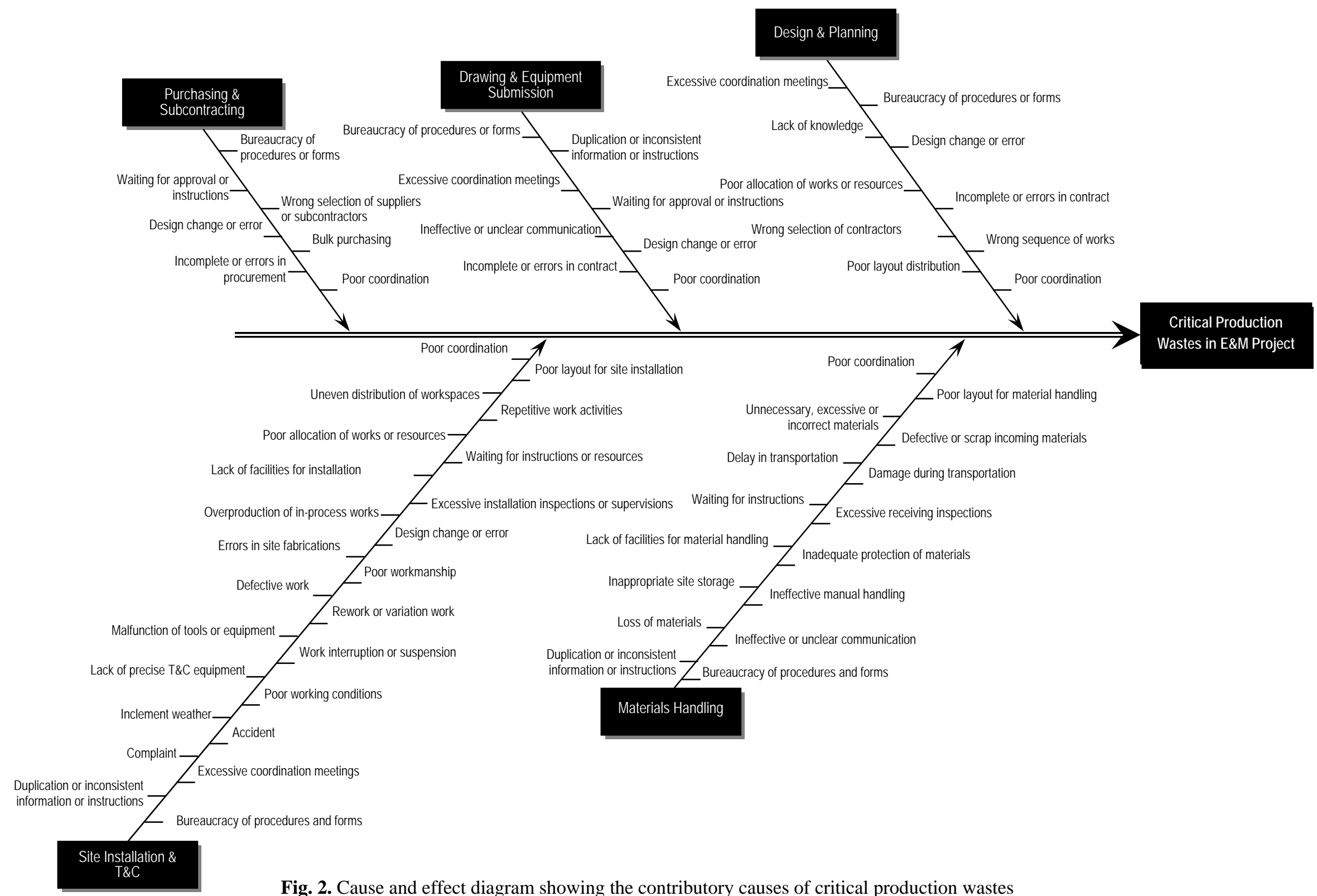




\section{Interviews with Frontline Site Supervisors}

Targeting deeper experiential knowledge in the next phase of the research, structured face-to-face interviews were conducted with 15 experienced site supervisors, each having around 8 to 17 years of on-site experience on E\&M construction projects. As shown in Table 2, all the interviewees with minimum 8 years on-site experience were specially chosen from a wide range of different trades of the E\&M sector including 3 from main contractors, 2 from consultants, 1 from package contractor and 9 from specialist contractors. A 5-point Likert scale well-designed questionnaire that was carefully planned and worded was used to determine if the views of supervisors converged, or not. As site observations were conducted in parallel with the site supervisors' interviews, deep knowledge and "base" (raw) findings could also be extracted in the study.

Table 2. Profile of the interviewees

\begin{tabular}{cccc}
\hline $\begin{array}{c}\text { Number of } \\
\text { interviewees }\end{array}$ & Trade of E\&M sector & $\begin{array}{c}\text { Avg. on-site } \\
\text { experience } \\
\text { (Years) }\end{array}$ & $\begin{array}{c}\text { Percentage } \\
\text { (\%) }\end{array}$ \\
\hline 3 & E\&M supervision in main contractor & $10-15$ & 20.0 \\
2 & E\&M consultant & $13-14$ & 13.3 \\
1 & E\&M package contractor & 17 & 6.7 \\
2 & Electrical system & $13-15$ & 13.3 \\
1 & Fire services engineering & 14 & 6.7 \\
2 & Heating, ventilation \& air-conditioning & $9-13$ & 13.3 \\
1 & Plumbing \& drainage & 16 & 6.7 \\
1 & Lift escalator & 10 & 6.7 \\
1 & Building automation & 15 & 6.7 \\
1 & Sewage and water treatment & 8 & 6.7 \\
\hline
\end{tabular}

Although the "sample size" may appear "small", the intensive interview interactions ensured clear understandings and unearthed deeper knowledge and more reliable response information than could be expected from a wider questionnaire survey (Fellows and Liu 1997). The interviewees were asked to comment on the extent of contributions to construction debris arising from the critical production wastes at different construction stages [i.e. design and planning, drawing and equipment submission, purchasing and subcontracting, materials control, site installation and testing \& commissioning (or T\&C)] of an E\&M construction project. A tailormade questionnaire with a 1 to 5 rating scale was used in the interview study. The results where importance factors (i.e. means) larger than 2.5 as perceived by the interviewees are shown in Table 3. 
Table 3. Importance of production wastes that contribute to construction debris at various stages

\begin{tabular}{|c|c|c|c|c|}
\hline Item & Description of production wastes & SD & Mean & Rank \\
\hline \multicolumn{5}{|c|}{ Design and planning stage } \\
\hline D01 & Poor coordination of processes or trades & 0.86 & 3.38 & 1 \\
\hline D03 & Wrong sequence of work activities & 1.09 & 3.27 & 3 \\
\hline D06 & Poor allocation of works or resources & 0.79 & 2.84 & 4 \\
\hline D07 & Design changes and/or errors & 0.71 & 3.53 & 2 \\
\hline D08 & Lack of knowledge about E\&M installations & 0.71 & 2.64 & 5 \\
\hline \multicolumn{5}{|c|}{ Drawing and equipment submission stage } \\
\hline S01 & Poor coordination of processes or trades & 1.14 & 2.53 & 2 \\
\hline S03 & Design changes and/or errors & 0.50 & 3.42 & 1 \\
\hline \multicolumn{5}{|c|}{ Purchasing and Subcontracting Stage } \\
\hline $\mathrm{P} 01$ & Poor coordination of processes or trades & 0.78 & 2.86 & 2 \\
\hline P04 & Design changes and/or errors & 0.89 & 3.54 & 1 \\
\hline P05 & Wrong selection of suppliers or subcontractors & 0.86 & 2.64 & 3 \\
\hline \multicolumn{5}{|c|}{ Material Control Stage } \\
\hline M01 & Poor coordination of processes or trades & 0.93 & 2.87 & 2 \\
\hline M03 & Unnecessary, excessive or incorrect materials & 0.82 & 2.79 & 3 \\
\hline M04 & Defective incoming materials & 1.27 & 3.39 & 1 \\
\hline M10 & Inadequate protection of materials & 0.70 & 2.64 & 5 \\
\hline M11 & Inappropriate site storage & 0.83 & 2.76 & 4 \\
\hline \multicolumn{5}{|c|}{ Site Installation and Testing \& Commissioning Stage } \\
\hline $\mathrm{I} 01$ & Poor coordination of processes or trades & 0.72 & 3.34 & 3 \\
\hline $\mathrm{I} 02$ & Poor layout for site installation & 0.87 & 3.03 & 5 \\
\hline $\mathrm{I} 02$ & Uneven distribution of work spaces & 0.84 & 2.53 & 9 \\
\hline $\mathrm{I} 10$ & Overproduction of in-process works & 0.77 & 2.90 & 7 \\
\hline I11 & Design changes and/or errors & 0.99 & 3.24 & 4 \\
\hline $\mathrm{I} 12$ & Errors in site fabrications & 0.84 & 3.02 & 6 \\
\hline $\mathrm{I} 13$ & Poor workmanship & 0.60 & 2.88 & 8 \\
\hline $\mathrm{I} 14$ & Defective work & 0.87 & 3.74 & 1 \\
\hline $\mathrm{I} 15$ & Rework or variation work & 0.86 & 3.37 & 2 \\
\hline
\end{tabular}

Note: Standard deviation (SD), mean and rank are tabulated respectively for 'production waste' where the importance factor (i.e. mean) larger than 2.5 as perceived by the interviewees. 


\section{Survey Results and Discussions}

\section{Design and Planning Stage}

Judging from Table 3, it is found that "poor coordination of processes or trades" and "change of design and/or errors in design" are considered the most important production wastes leading to construction debris at the design and planning stage. This yields an impressive result that is in line with the findings of numerous researchers: that design changes and/or errors will lead to construction debris even before the installation activity has commenced. A few site supervisors pointed out that most of the E\&M contractors are not involved in any design or planning process, but they are required to produce shop drawings based on the designs and specifications and coordinate further installation works. The upstream design changes and/or errors, in particular of ductwork or pipework installations will enormously lead to much repetitive works or reworks. Design and documentation errors frequently cause clashes amongst E\&M trades, as well as with other trades in a construction project, and non value-adding demolition and replacement may be required consequential to variations.

\section{Drawing and Equipment Submission Stage}

Similar to the findings at the design and planning stage, the significant production wastes as identified previously as the important contributors to construction debris are still highly rated when comparing with other production wastes at the submission stage. The site supervisors contended that the E\&M contractors often inherit designs from the project architect and other consultants and any design change and/or error will trigger repetitive works, variations and/or reworks. This also plays an important role in contributing to construction debris arising out of demolition or replacement of early stage installed works such as conduit routings, ductwork, pipework, trunking, etc.

\section{Purchasing and Subcontracting Stage}

As shown in Table 3, change of design and/or errors in design, is still considered as a key factor that contributes to construction debris during the purchasing and subcontracting stage. More than $70 \%$ of the site supervisors expressed that design changes cause variations to previously approved equipment submissions, and those can well affect their procurement as well. It is commonly accepted that an extra 5-10\% of materials should be ordered to allow for site wastage through damage, spillage, over-supply and vandalism (Coventry and Woolveridge 2002). However, it is believed that much of the incorrect equipment will not contribute to construction debris, as most equipment in the Hong Kong E\&M sector will be finalised and purchased by the site engineers at the "eleventh hour" and even delivered before a purchase order can be processed. In case of any incorrect procurement, the equipment can be returned to the suppliers or retained for other construction projects. If so, while there is production waste, there is no additional debris in such cases. However, frequent changes or errors in design can still contribute to construction debris at the purchasing and subcontracting stage, because much extra time is spent by the site supervisors for investigating, administering and coordinating these varied procurement works, while on-site monitoring of the installation activities may be delegated to inexperienced or unskilled foremen. This can therefore contribute to more defective works or even reworks as the inexperienced or unskilled foremen may not be capable to identify minor defects at the source before turning into large defective works. Meanwhile, design changes and/or errors also cause 
variations to early installed works such as conduit routing, ductwork, pipework, trunking, etc. Their modification, demolition or replacement will inevitably contribute to construction debris. It is worthwhile to mention that at the purchasing and subcontracting stage, "wrong selection of suppliers or subcontractors" is one of the major items that contribute to construction debris because substandard suppliers or subcontractors are not equipped to organize and execute their works in a professional manner, hence triggering further problems such as defects, inadequate protection, excessive on-site fabrication, poor work control, and all these may contribute to further construction debris.

\section{Material Control Stage}

As depicted in Table 3, "defective incoming materials" is a major factor that contributes to the construction debris at the material handling stage. It is understandable that any defective material is disposed of as construction debris at landfills but only a few of the site supervisors indicated that handling of these materials takes extra time, effort and resources that may ultimately slow down the overall construction progress. One site supervisor stated that any defective incoming bathtubs and latrines will mostly be disposed of as construction debris and he explained that only a few of the materials can be directly delivered to, and sorted at, the point of use and therefore are handled more than once. This may increase the probabilities of material defects. On the other hand, it was identified previously that "poor layout for material handling" in respect of on-site material storage and handling was rated highly as a major production waste. Even though this factor was not highly rated as a key factor that contributes to construction debris, it is believed that the layout is probably arranged by the main contractor or other upstream parties, and the lack of coordinated planning with subcontractors leads to argument, waiting, interference with other trades and even damage to materials and equipment.

\section{Site Installation and T\&C Stage}

Table 3 indicates that "defective work", "rework or variation work" and poor coordination of processes or trades are perceived as key production wastes by the site supervisors that may contribute to construction debris during the site installation and T\&C stage. Nearly $90 \%$ of the site supervisors explained that the requirements for quality work by clients, architects or building services inspectors has become stringent and demanding. In fact, excessive on-site fabrication such as drilling, cutting and painting may contribute to defects, and demolition. Then replacement or rework may be required for any defective or substandard work. The changes or errors in design will cause variations to installed work that can largely increase the quantity of construction debris arising from demolition or replacement. A few interviewed site supervisors expressed that rework or variation induced work is one of the key de-motivation factors when asked to demolish their installations. Meanwhile, the E\&M industry requires good coordination amongst different processes and trades. Poor coordination may result in conflict with other services because ductworks, pipeworks, conduit works, connecting boxes, cable trays, etc may be shown to be neatly connected in a shop drawing, but in reality this may require significant amounts of extra space or variation works to other services in order to achieve the designated layout. On the other hand, the E\&M trades are always subcontracted out, down to several tiers and the team spirit of the entire E\&M sector seem to be weak given the regular conflicts in most projects. This also results in poor coordination of site installation between crews in various trades. The situation is also experienced during the T\&C stage because poor coordination between various trades may result in idling when one trade is ready for testing and commissioning but must wait because other trades are not ready. All these factors may contribute to significant amounts of non-value-adding construction debris. 
In summary, the critical production wastes are taken to be those where the mean value is larger than 2.5 that contribute to construction debris at different construction stages as perceived by the experienced site supervisors. It is found that change of design and/or errors in design is one of the critical production wastes that recurs frequently and may contribute to construction debris at different stages of an E\&M construction project. A typical example is that the E\&M contractor has already completed the installation of a section of the system prior to receipt of the Architect's Instruction involving design change and/or errors resulting in demolition of the completed works and reinstallation pursuit to the new design. This seems to suggest that design variations are sometimes wasteful as mentioned by Coventry and Guthrie (1998) and it is necessary to make the design and the construction process flexible enough to accommodate changes before interdependent assembling of E\&M in-process products without wastage. Where the design team has not determined the final version of the design with the client for a certain part of the project, the contractor should be informed as early as possible so as not to build, demolish and rebuild that part, leading to both production waste and construction debris. The design and construction process should be made flexible so that the overall programme is not disrupted, while the contractor need not carry out abortive works. The design and construction teams should work closely together in true partnering spirit to facilitate communication and coordination in the process. Meanwhile, it is observed that a total of five factors appear as critical production wastes at the site installation and T\&C stage and this indicates that even more attention is needed at this stage as perceived by the site supervisors. It also reveals that most of the site supervisors are only involved in the site installation and T\&C processes, particularly for infrastructure projects, and these production wastes will critically hinder their productivity in E\&M works. This is verified from the fact that the total number of critical production wastes is comparably lower at the drawing and equipment submission, purchasing and subcontracting and material control stages.

\section{Feedback and Conclusions from the Second Industry Focus Group Meeting}

While collecting and compiling the above findings, it was considered important, as also advocated by Meredith et al. (1989), to understand how industry practitioners view the findings and also the measures suggested to address some of the identified issues. A specially convened focus group meeting of 10 senior and mid-level construction practitioners including the first and third writers was organised on March, 222007 to discuss the findings and review and refine the appropriateness of improvement strategies. The group has a wide representation adequately covering the supervisory and frontline management in the sector including 3 senior managerial practitioners, 2 mid-level managerial practitioners, 1 government official, 4 frontline engineers and supervisors selected from the sector.

Ninety percent (9 of 10) of the attendees agreed that the critical production wastes identified in the structured interview survey could contribute to construction debris and some $70 \%$ agreed with the statement that the present levels of construction debris due to replacement, demolition and rework would not have been created in the first place as mentioned by Gavilan and Bernold (1994) and Snook et al. (1995) if more improvement strategies had been adopted before interdependent E\&M installations or assemblies became non value-adding debris arising out of poor coordination and design change and/or error.

Eighty percent conveyed that good coordination in E\&M sector was of paramount importance due to the occurrence of conflicts in particular of false ceilings, horizontal and vertical ducts and/or pipes, conduit works. The conflicts result in demolition, replacement and/or rework that inevitably contribute to construction debris. Some of the attendees opined that the occurrence of services conflicting with the structure, space or each other in Hong Kong E\&M sector is of 
especially paramount importance in the Hong Kong where installation space is limited. Although the exact locations of various services are defined on the drawings, poor workmanship will lead to deviations from the original intent, thus creating conflicts between services. Meanwhile, there may not exist the required types of fittings, holes and fixings to suit the site constraints, so at time, two or more elbows or bends may have to be installed and create conflicts between services. More importantly, the subcontracts are still awarded to different companies making sequential construction difficult. A typical example is that the subcontractors will try to work fast to prevent being trapped in the critical path and being responsible for the liquidated damages in case of delay. They may prefer more variation claims arising from design changes and/or errors and obstructions and/or conflicts with other services, and not be concerned with the fact that construction debris will increase from the resulting demolition, replacement and rework.

Table 4. Good practices when handling E\&M materials and equipment on site

\begin{tabular}{|c|c|c|c|c|c|c|c|c|c|c|c|}
\hline & & \multicolumn{10}{|c|}{ E\&M materials and equipment } \\
\hline & & 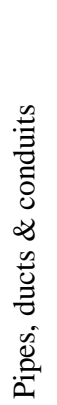 & 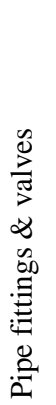 & 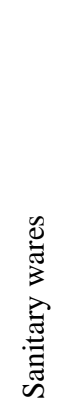 & 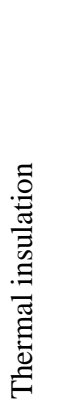 & $\begin{array}{l}\frac{n}{\ddot{U}} \\
\frac{\pi}{n} \\
\frac{\pi}{\pi} \\
\sum\end{array}$ & 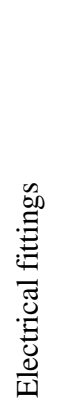 & 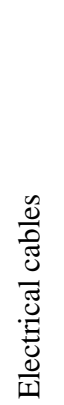 & 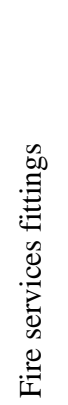 & 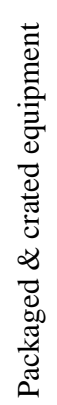 & \\
\hline 1 & Segregate into sizes and grades & $*$ & $*$ & & * & & $*$ & $*$ & $*$ & & * \\
\hline 2 & Enclosed \& lockable store room & & & * & & & $*$ & * & $*$ & * & * \\
\hline 3 & Sheltered open store areas within site boundary & * & * & & * & * & & & & & \\
\hline 4 & Enclosed pallets or containers & & $*$ & & & & $*$ & & $*$ & & \\
\hline 5 & Original packaged protections & & & * & * & & & & & $*$ & \\
\hline 6 & Store to allow easy lifting by tower crane & $*$ & & * & & & & & & $*$ & \\
\hline 7 & Protect and label adequately after installation & $*$ & & * & & & $*$ & * & * & $*$ & \\
\hline 8 & On-site sorting for recycling & $*$ & & & & * & & $*$ & & & \\
\hline 9 & On-site sorting for reuse & & * & * & & * & $*$ & & * & $*$ & \\
\hline
\end{tabular}

Seventy percent of the attendees indicated that design change and/or error recurred frequently and were satisfied that design uncertainties should be resolved completely before proceeding with any assembly or installation on site. A few attendees opined that interdependent assembly work should not begin unless the availability of space, resource and "error-free" design or instruction is confirmed. This seems to suggest that design decisions can be postponed until prerequisite work is completed and unobstructed access and workspace such as pipework crossover, branching, cable bending radii and so on are available as advocated by Gil et al. (2001) and Tommelein and Ballard (1997). The early involvement, especially of the E\&M engineer and the contractor can be more beneficial for providing environmentally responsible solutions (Rawlings 1999). This appears comparably more important than some others specialties because 
of the highly interdependent nature of E\&M sector. Eighty percent of the attendees expressed that there would be fewer defects if the concept of mistake-proofing was applied and they also pointed out the need to acquire multi-tasking workers for performing self-checks and successive checks. More importantly, the concept of reduce, reuse and recycle could be reinforced in mistake-proofing checks before dumping to landfill. More than eighty percent of the attendees agreed that the reduction of demolition and/or replacement was not only helpful for reducing construction debris but developing a motivated and collaborative team and this is probably one of the spin-off benefits when poorly coordinated and highly interdependent E\&M crews are motivated in producing value-adding works. Several good practices for handling major E\&M materials and equipment on site as collected during the survey and reviewed in the focus group are summarized in Table 4.

The focus group referred to the research findings and the pillars of "Just-In-Time". They went on to suggest a "4D3R" guiding principle in the Hong Kong E\&M sector to reduce construction debris. What seems to be important is "Do it right the first time", "Do only when necessary and conflict-free", "Do only what will add value unless inevitable" and "Do any inevitable demolition based on 3R principle" for the entire process flow of a project and this also relates to the flow pattern as illustrated previously in Fig. 1. According to the key performance indicators for environmental issues to what extent the E\&M contractors control environmental impacts including material wastes during installations, the mean score is only 6.6 and the percentage of contractors scoring 8 or more is only 41\% (BSRIA 2004). The 4D3R guiding principle appears crucial for modifying the traditional production systems. It is believed that the non-value-adding productions components could be reduced largely if the flow pattern is followed as replacement, demolition and rework will be minimized, and ultimately, construction debris could then be reduced to a certain extent. The general conclusion appears to present another convincing argument in favour of the reduction of the "making-do waste" which is the eighth category of production waste as recommended by Koskela (2004), because the uncertain inflows to the tasks can be reduced if the 4D3R guiding principle is adopted. Of course further research efforts focusing on these aspects are still required before a final conclusion.

\section{Conclusion}

The large volume of construction debris is one of the critical environmental problems in the Hong Kong construction industry and it is likely to get worse. The debris mountain arising from the E\&M sector itself is huge and it continues to grow at an alarming rate. This study demonstrates that critical production wastes such as poor coordination, design change and/or error, defective work and rework or variation can contribute to considerable construction debris in an E\&M project. It is found from the structured in-depth interview study that any changes and/or errors in design cause a very high amount of reworks or variation works. This is a critical factor that contributes to construction debris. It is suggested that an "error-proof" design must be targeted for at the planning and design stage, by re-validating each design when something goes wrong, instead of accumulating errors, and ending up with a huge problem such as in variation work or rework. On the other hand, the concept of mistake-proofing that has long been applied in the manufacturing industry to promote zero defects in a production line can now be transformed into a new strategy to ensure that sequential material handling, site installation and $\mathrm{T} \& \mathrm{C}$ processes are implemented in a "defect-free" manner in construction projects. All these are motivation factors that can enhance coordination between processes and trades and boost the team spirit of the entire E\&M sector of the industry.

If the identified critical production wastes at different construction stages of an E\&M project can be minimised at their sources, the quantity of construction debris can be effectively and 
economically reduced. Meanwhile, the new flow pattern and 4D3R guiding principle as suggested in the paper appears practicable for reducing construction debris, as some of the indirect construction debris produced from the incidental work can now be reduced or even transformed to value-adding work. This would be in preference to immediate dumping as construction debris directly from the construction sites to growing scarce public fill or landfill sites in Hong Kong. This can ultimately increase the overall productivity of the industry and also cultivates sustainable and green practices on sites from an E\&M sector initiative in the Hong Kong construction industry in the first instance. Of course, surveys using similar approaches could identify critical "production wastes" and sources of construction debris in the E\&M sectors elsewhere. The flow pattern model and recommended strategies could then be adapted for different countries using a similar methodology. Although the sample size of 15 may be considered small in some scenarios, the in-depth and reliable knowledge harnessed from handson supervisors in this case is seen as valuable. It provides a solid basis to identify the critical factors, to justify the proposed new flow pattern and to formulate interim recommendations as in the paper. A larger scale study is being planned to delve deeper into how else the critical factors can be addressed, and how exactly the proposed flow pattern can be implemented in terms of reduction, transformation, recovery and reuse.

\section{Acknowledgement}

The authors gratefully acknowledge all the interviewees in the survey, as well as the RGC Research Grant No. HKU7138/05E and the Analogue Group of Companies for providing necessary support in the research.

\section{References}

Alarcón, L. F. (1994). “Tools for the identification and reduction of waste in construction project." Proc., $2^{\text {nd }}$ Workshop on Lean Construction, IGLC, Santiago de Chile.

Borcherding, J. D., and Alarcón, L. F. (1991). "Quantitative effects on construction productivity.” The Construction Lawyer, 11(1), 35-48.

Bossink, B. A. G., and Brouwers, H. J. H. (1996). "Construction waste: quantification and source evaluation.” J. Construction Engineering and Management, 122(1), 55-60.

BSRIA (2004). Key performance indicators for M\&E contractors - 2004: handbook and guidance, BSRIA, Berkshire, Bracknell.

Coventry, S., and Guthrie, P. (1998). "Waste minimisation and recycling in construction - design manual.” CIRIA Special Publication 134, CIRIA, London.

Coventry, S., and Woolveridge, C. (2002). "Environmental good practice on site.” CIRIA C502, CIRIA, London.

Dicks, M. (2003). “Innovative M\&E data sheets.” BSRIA Guidance Note ACT 5/2002, BSRIA, Berkshire.

Ekanayake, E. L., and Ofori, G. (2004). "Building waste assessment score: design-based tool.” Building and Environment, 39(2004), 851-861.

Emiliani, M. L. (1998). “Lean behaviours.” Management Decision, 36(9), 615-631.

EPD (Environmental Protection Department) (2007). “The problem." Introduction to Construction Waste, <http://www.epd.gov.hk/epd/misc/cdm/introduction.htm> (Mar. 11, 2007).

EPD (Environmental Protection Department) (2008). Monitoring of solid waste in Hong Kong waste statistics for 2007, Environmental Protection Department, Hong Kong. 
Faniran, O. O., and Caban, G. (1998). "Minimizing waste on construction project sites engineering.” Construction and Architectural Management, 5(2), 182-188.

Fellows, R., and Liu, A. (1997). Research methods for construction, Blackwell Science, Oxford.

Formoso, C. T., Soibelman, L., Cesare, C. D., and Isatto, E. L. (2002). "Material waste in building industry: Main causes and prevention." J. Construction Engineering and Management, 128(4), 316-325.

Franklin and Andrews (2003). Construction benchmarks property (little black book), Franklin \& Andrews, England.

Faniran, O. O., and Caban, G. (1998). "Minimizing waste on construction project sites engineering." Construction and Architectural Management, 5(2), 182-188.

Gavilan, R. M., and Bernold, L. E. (1994). "Source evaluation of solid waste in building construction.” J. Construction Engineering and Management, 120(3), 536-552.

Gil, N., Tommelein, I. D., and Kirkendall, R. (2001). "Modelling the design-build development process for a facility component." Proc., $9^{\text {th }}$ Annual Conference of the International Group for Lean Construction, IGLC, Singapore.

Halliday, S. P. (1994). Environmental code of practice for buildings and their services, BSRIA, Berkshire.

Hanna, A. S., Peterson, P., and Lee, M. J. (2002). "Benchmarking productivity indicators for electrical/mechanical projects.” J. Construction Engineering and Management, 128(4), 331-337.

Jayawardane, A. K. W. (1998). "Material and labour wastage on Sri Lankan construction sites." NICMAR J. Construction Management, 13(3), 221-239.

Kumaraswamy, M. M., Ling, F. Y. Y., Rahman, M. M., and Phng, S. T. (2005). "Constructing relationally integrated teams.” J. Construction Engineering and Management, 131(10), 1076-1086.

Koskela, L. (1992). "Application of the new production philosophy to construction.” Technical Report 72, Centre for Integrated Facility Engineering, Stanford University, Stanford.

Koskela, L. (2004). "Making-do - the eight category of waste." Proc., 12th Annual Conference of the International Group for Lean Construction, IGLC, Copenhagen, Denmark.

Macomber, H., and Howell, G. (2004). "Two great wastes in organizations.” Proc., $12^{\text {th }}$ Annual Conference of the International Group for Lean Construction, IGLC, Copenhagen, Denmark.

Meredith, J. R., Raturi, A., Amoako-Gyampah, K., and Kaplan, B. (1989). "Alternative research paradigms in operations.” J. Operations Management, 8(4), 297-326.

Ohno, T. (1998). Toyota production system, Productivity Press, Portland.

Olnhoff, V., and Martin A. (2003). "Recycling building services.” A BSRIA Guide BG 16/2003, BSRIA, Berkshire.

PLB (Planning and Lands Bureau) (2001). "People first - a caring approach to urban renewal." Urban Renewal Strategy, Planning and Lands Bureau, Hong Kong.

Plossl, G. W. (1991). Managing in the new world of manufacturing: how companies can improve operations to compete globally, Prentice-Hall, Englewood Cliffs.

Rawlings, R. H. D. (1999). "Environmental case studies - volume 2.” BSRIA Case Studies CS 16/99, BSRIA, Bracknell.

Shen, L. Y., and Tam, V. W. Y. (2002). "Implementation of environmental management in the Hong Kong construction industry.” International Journal of Project Management, 20(7), 535-543.

Shingo, S. (1981). Study of Toyota production system from industrial engineering viewpoint, Productivity Press, Tokyo.

Skoyles, E. F. (1976). "Material wastage: A misuse of resources.” Building Research and Practice, 1976, July/April, 232-243.

Skoyles, E. R., and Skoyles, J. R. (1987). Waste prevention on site, Mitchell Publishing, London. 
Snook, K., Turner, A., and Ridout, R. (1995). Recycling waste from the construction site, CIOB, England.

Standard, C., and Davis, D. (1999). Running today's factory: a proven strategy for lean manufacturing, Hanser Gardner Publications, Cincinnati.

Tam, V. W. Y., Tam, C. M., Chan, J. K. W., and Ng, W. C. Y. (2006). "Cutting construction wastes by prefabrication.” The International Journal of Construction Management, 2006, 15-25.

Tao, W. K. Y., and Janis, R. R. (1997). Mechanical and electrical systems in buildings, Prentice Hall, Upper Saddle River.

Tommelein, I. D., and Ballard, G. (1997). “Coordinating specialists.” Technical Report 97-8, CEM Program, University of California Berkeley.

Vaid, K. N. (1996). "Waste control of building materials in construction of mass housing project.” NICMAR J. Construction Management, 11(4), 367-394.

Womack, J. P., and Jones, D. T. (1996). Lean thinking: banish waste and create wealth in your corporation, Simon \& Schuster, New York.

Urio, A. F., and Brent, A. C. (2006). "Solid waste management strategy in Botswana: the reduction of construction waste.” J. South African Institution of Civil Engineering, 45(2), $18-22$. 